\title{
Lead Plant
}

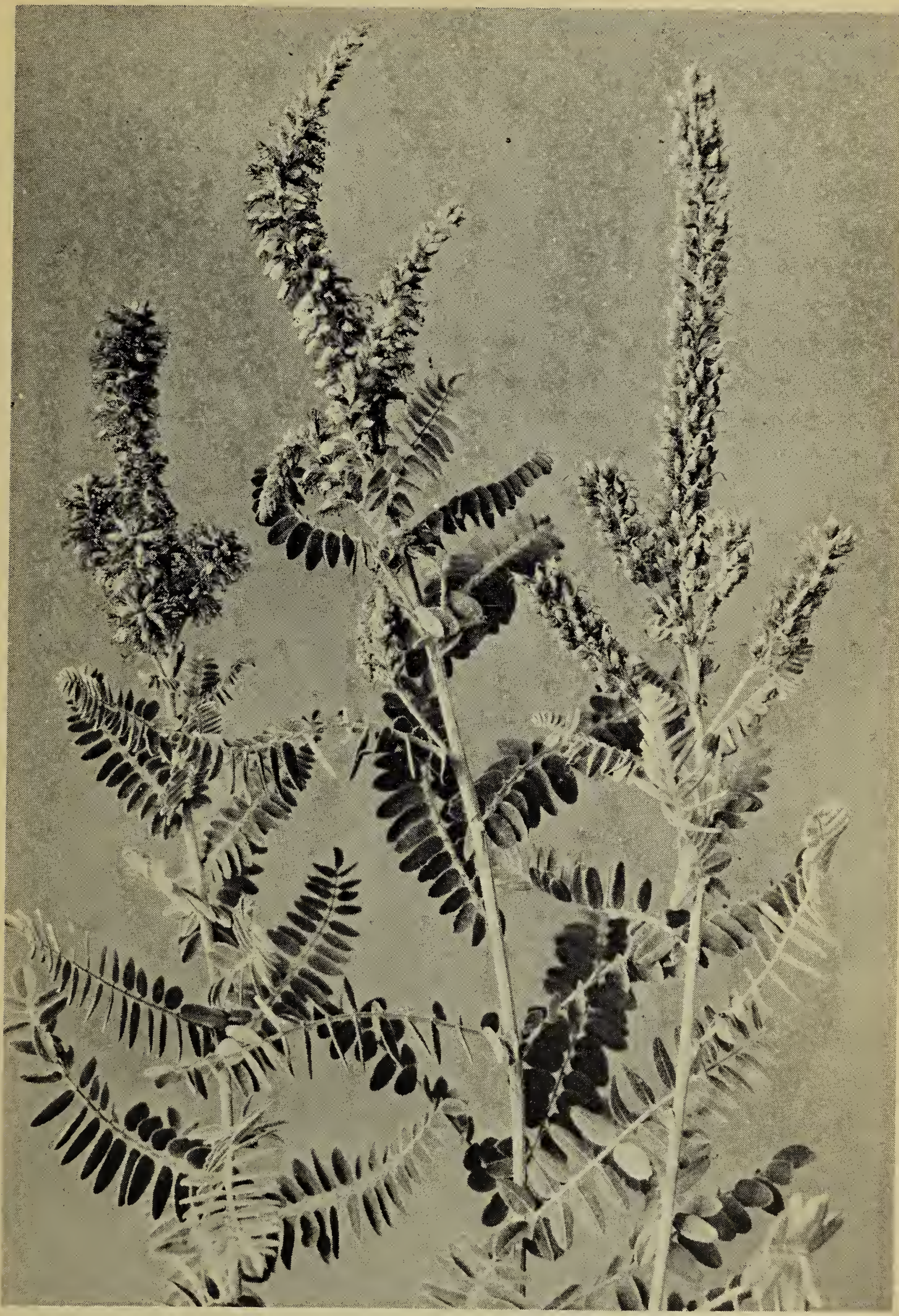

Photo by the late Dr. W. C. McCalla

\section{Amorpha canescens Nutt.}

The Greek word "amorphos" means deformed. The Lead Plant is a legume but the flowers are without wings and keel, the standard is small and bluish. This two to three foot shrub only extends west to the southeast corner of Saskatchewan. The above photo was taken in Manitoba. 